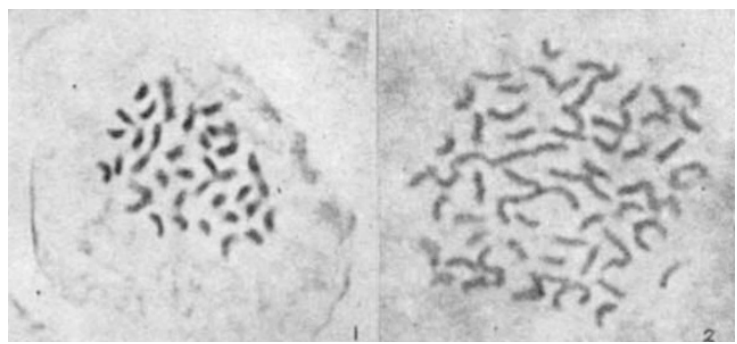

Somatic metaphase plate of (1) C. dichotomum L., showing 38 chromosomes; (2) C.tomentosum L., showing 72 chromosomes. $\times 1,500$

The count of $2 n=144$ for $C$. alpinum L. is only an approximation, as an accurate count has not yet been possible. The number certainly exceeded $2 n=108$ and $2 n=72$, which $\mathrm{I}^{1}$, and other workers $^{3-5}$, have previously recorded for $C$. alpinum $\mathrm{L}$. It would appear that this species contains a polyploid series, $2 n=72,2 n=108,2 n=144$.

Otive E. Brett

Department of Botany, Queen Mary College,

University of London, E.1. June 23.

${ }^{1}$ Brett, O. E., Nature, 166, 446 (1950).

${ }^{2}$ Rohweder, H., Beih. Bot. Centralblatt, 59B (1939).

${ }^{3}$ Böcher, T. W., Svensk. Bot. Tid., 32 (1938).

${ }^{4}$ Löve, A., and Löve, D., Arkiv för Bot., 31 (1944).

'Löve, A., and Löve, D., J)ept. Agric. Rep., Reykjavik, Series B, No. 3 (1948).

\section{Statistical Methods in Anthropology}

There has been a lively discussion, in Nature ${ }^{1}$ and elsewhere ${ }^{2}$, on the classification of recent fossil finds in South Africa. Prof. S. Zuckerman has rightly stressed the need for basing such decisions on statistical tests. But his findings have been at odds with those based on classical comparisons; so that anthropologists must now be in doubt whether their seience has, indeed, anything to learn from statistics.

This unhappy result can be traced to the piecemeal tests which have hitherto been used. A bone or a tooth is a unit; it is not a discrete assembly of independent measurements. To compare its single variates one by one, as Ashton and Zuckerman have done $^{3}$, is both inconclusive and misleading. Inconclusive, because nothing is decided when it is shown that, say, the height of an incisor lies in the range of heights of gorilla incisors, and the breadth lies in the range of breadths of chimpanzee incisors-a state of affairs which may well be characteristic of a species different from both; and misleading, because tests based on dimensions which are correlated are themselves not independent, and little is gained by accumulating them.

The right statistical method must treat the set of variates as a single coherent matrix; and this is, in fact, the technique of multivariate analysis. Consider, for example, four measurements (in millimetres) of a lower milk canine: $x_{1}$ the height, $x_{2}$ the maximum anterior-posterior length of the upper half, $x_{3}$ the maximum breadth of the upper half, and $x_{4}$ the maximum anterior-posterior length at the level of the basal cingulum. Also consider the problem, in the first place, of discriminating between two species
- say, chimpanzee and man. Then the measurements should be combined in a single discriminating function,

$$
X=a_{1} x_{1}+a_{2} x_{2}+a_{3} x_{3}+a_{4} x_{4},
$$

where the constants $a_{1}, a_{2}, a_{3}, a_{4}$ are to be calculated from the averages, the variations, and the correlations, of the measurements within both species.

The discriminant we obtain in this way, using the measurements of forty human and forty-four chimpanzee milk canines, is

$$
X=x_{1}-7 \cdot 49 x_{2}+2 \cdot 34 x_{3}+4 \cdot 70 x_{4},
$$

and this has on the average the value

$$
X=+17 \cdot 6 \text { for the chimpanzee, }
$$

and has the average value

$$
X=-5 \cdot 0 \text { for man. }
$$

The standard deviation of $X$ is 2.45 ; so that the range of $X$, taken at $2 \frac{1}{2}$ times the standard deviation, is $6 \cdot 1$ on either side of the average.

In order to classify a tooth, which is supposed to be either a human or chimpanzee lower milk canine, $x_{1}, x_{2}, x_{3}, x_{4}$ are measured in millimetres, and the measurements inserted in the discriminant function (2) above. If the result lies between $+23 \cdot 7$ and $+11 \cdot 5$ the tooth is chimpanzee; if between $+1 \cdot 1$ and $-11 \cdot 1$ it is human. For all the eighty-four teeth the measurements of which we have had, this test is decisive. The supposition that a tooth belongs to one of these two groups is at least strengthened by the fact that its value of $X$ falls into one of the two ranges.

As an application, we have calculated the value of the discriminant function given by (2) for the Kromdraai and the Taungs milk canines found in South Africa. The values are -2.6 and -7.9 respectively. They demonstrate conclusively that these teeth do not belong to the chimpanzee group. More than this, they fall precisely in the human range. It would be wrong on this ground alone to conclude positively that they are human teeth; for the measurements might, for example, be matched on an object which turns out to be a pebble or a fake. But within the limits of the present comparison, the statistical evidence is that these teeth belong to the human family.

These methods of discrimination need not be confined to a choice between two alternatives. The technique of multivariate analysis makes it possible to construct functions to discriminate at one time between a number of species, and we hope elsewhere to construct such functions for human, chimpanzee, gorilla and orang-utan teeth. These functions can, we believe, have an important place in biological classification, for which indeed they were first designed. They show that the methods of modern statistics are not alien to anthropology, but are capable of assessing a fossil or a limb as a unit, and not as a haphazard jumble of piecemeal measurements.

Cleeve Hill,

\section{J. BRONOWSKI}

W. M. LoNG

Cheltenham.

Aug. 31.

'Zuckerman, S., Nature, 165, 652; 168, 158, 953 (1950). Le Gros Clark, W. E., Nature, 165, 893; 166, 791 (1950).

${ }^{2}$ Le Gros Clark, W. E., Man, 51, 18 (1951). Zuckerman, S., Man, 51,20 (1951).

${ }^{3}$ Ashton, E. H., and Zuckerman, S., Phil. Trans. Roy. Soc., B, 234, 471 and $485(1950) ; M a n, 51,23$ (1951). 